Article

\title{
Impacts of Returning Unsold Products in Retail Outsourcing Fashion Supply Chain: A Sustainability Analysis
}

\section{Bin Shen * and Qingying Li}

Glorious Sun School of Business and Management, Donghua University, Shanghai 200051, China; E-Mail: liqingying@dhu.edu.cn

* Author to whom correspondence should be addressed; E-Mail: binshen@dhu.edu.cn; Tel.: +86-21-6237-3621.

Academic Editor: Alessio Ishizaka

Received: 19 November 2014 / Accepted: 13 January 2015 / Published: 23 January 2015

\begin{abstract}
Retail outsourcing with a return policy is quite commonly adopted in the fashion supply chain. Under the return policy, the supplier as a brand owner may focus on production, and then outsource retailing to the retailer. In the meanwhile, the retailer may receive some support money from the supplier for subsidizing the loss of unsold products at the end of the selling season and be asked for shipping back. Motivated by this real practice in the fashion industry, we examine a two-echelon supply chain with one supplier and one retailer under the return policy. Several interesting findings are obtained from our analysis. First, we find that when the supply chain achieves channel coordination, the cost of physical return is at least partially borne by the supplier, no matter who is responsible for it in reality. Second, we find that the cost of physical return is significantly affecting the sustainability factors such as the expected amount leftover (which represents environmental friendliness), the expected sales to expected goods leftover ratio (which implies both environmental friendliness and economic sustainability), and the rate of return on investment (which indicates economic sustainability). Third, from a sustainability perspective, we find that the pure wholesale price contract is more sustainable than the coordinating return policy. A numerical study by the real company data is conducted and managerial insights from analysis are discussed.
\end{abstract}

Keywords: return policy; cost of physical return; supply chain coordination; sustainability analysis 


\section{Introduction}

In fashion supply chains, the supplier as a brand owner may outsource retailing to the retailer, who is responsible for selling products to end consumers. Due to quickly changing consumer taste, the retailers may hold large amounts of unsold products $(25 \%-40 \%)$ at the end of selling season [1]. According to Mostard and Teunter [2], the unsold trendy fashion products may be as high as $74 \%$ compared to the initial startup inventory. This potentially large amount of unsold products definitely hurts the fashion retailers and worsens their profit. To help retailers and to sustain the fashion business, it is no secret that fashion retailers may receive some support money from the suppliers for subsidizing the loss and returning the unsold products at the end of the selling season. This is the so-called "return policy". The return policy we discuss in this paper is adopted between retailers and suppliers in supply chain, rather than between retailers and consumers. The return policy is an efficient strategy in reverse supply chains. Under the return policy, it is voluntary for the retailer to return the unsold products. The supplier then can re-sell these returned products to another market or recycle them in a sustainable manner. As such, the residual value of unsold products is increased. Reverse supply chains are an important part of sustainable fashion supply chains $[3,4]$. The return policy is able to significantly affect the efficiency of reverse supply chains [5]. Therefore, it would be interesting to investigate the sustainability of return policies in supply chains.

According to our observations, the return policy has been widely adopted in retail outsourcing fashion supply chains. For instance, in the U.S., fashion department stores including Saks, Kohl's, and J.C. Penney would receive a buyback credit from the fashion brands (i.e., suppliers) such as Tommy Hilfiger, Ralph Lauren, and the Jones Apparel Group at the end of the selling season [6]. This strategy is quite common in the fashion industry, not only in the U.S., but also in China. For example, we observe that a Chinese fashion company, LX (i.e., a supplier), implements a retail outsourcing strategy in supply chains with the return policy (due to confidentiality issues, LX is a fictitious name). LX is a fashion company, producing apparel and accessories. LX allows its franchising retailers (in the franchising business, the supplier outsources retailing to the franchising retailer who is responsible for selling) to return the unsold products at the committed price (i.e., the return price). The case of LX motivates us to further explore the impact of the cost of physical returns with a return policy in fashion supply chains. Hence, the objectives of this paper are to address the following questions.

(1) How does the cost of physical return affect supply chain coordination?

(2) How does the cost of physical return affect sustainability in such a reverse fashion supply chain?

(3) Is the return policy more sustainable in fashion supply chains compared to the traditional wholesale price contract?

To achieve the objectives above, we study a two-echelon fashion supply chain with one supplier (i.e., a brand owner) and one retailer selling a short-life fashion product under the return policy. Studying the impact of unsold products in retail outsourcing fashion supply chains fills the gap in the existing literature and yields the following new insights. First, we examine the impacts of the cost of physical returns on supply chain performance and find that the cost of physical return is at least partially borne by suppliers, no matter who is responsible for it in reality. Second, we study how the cost of physical return affects the sustainability factors. We find that if the cost of physical return is lower, the expected quantity of goods leftover (which represents environmental friendliness) is higher, and the ratio 
of expected sales to expected quantity of goods leftover (which implies both environmental friendliness and economic sustainability) and the expected rate of return on investment (which indicates economic sustainability) are higher. This implies a low logistic cost for returning unsold products may not be beneficial to supply chain sustainability. Third, we compare the economic sustainability results under the return policy with those under the benchmark pure wholesale price contract. We find that under the return policy, the expected quantity of goods leftover is higher, and both the ratio of expected sales to expected quantity of goods leftover and the expected rate of return on investment are lower than those under the wholesale price contract. From a sustainability perspective, the pure wholesale price contract is more sustainable than the coordinating return policy. In this paper, we are motivated by real practices in the fashion industry and we conduct a numerical study based on real industry data. Our results provide the managerial insights to fashion supply chains.

The organization of the rest of this paper is given as follows. We first show the related literature of return policy and the cost of physical return in fashion supply chains in Section 2 . The model is presented in Section 3.Section 4 studies the sustainability analysis and Section 5 shows numerical study used by the real company data. This article ends with a conclusion in Section 5.

\section{Literature Review}

The return policy implies that the retailer is allowed to return the unsold products to the supplier. It is well known that the return policy can help supply chains achieve coordination. Pasternack [7] was the first one to study using the return policy to coordinate supply chains. Later, Krishnan et al. [8] examine channel coordination with the return policy in supply chains when the market demand is affected by promotional sales effort. They find that the single return policy is not able to achieve supply chain coordination with promotional sales effort. They discuss the hybrid contract with effort sharing, unilateral markdown allowances, and buybacks contingent on a sales target for channel coordination. Cachon and Lariviere [9] find that when supply chain coordination is achieved, the return policy is able to split the total supply chain profit by the provision of buyback credit, which is equivalent to revenue sharing contracts. Wang and Webster [5] examine how the return policy with gain/loss sharing coordinates supply chains. Their analytical and numerical results indicate that such a contract is able to improve performance of supply chains and their agents. In this paper, our focal point is supply chain performance under supply chain coordination, instead of achievability of supply chain coordination.

The return policy has been extensively investigated in literature because of its popular adoption in the fashion industry. Donohue [10] examines the impact of forecast information on channel coordination with the return policy in fashion supply chains. They find that if the market information is less predictive, a Pareto improvement does not possibly exist. Kurata and Yue [11] examine the performance of the scan-back trade deal, which is a special type of trade promotion in fashion supply chains. They find that the return policy coupled with the scan-back trade deal is able to achieve supply chain coordination and be beneficial to the profits of both the retailer and the supplier.

As we have discussed, the return policy is closely related with sustainability. Lately, Choi [12] examines the optimal sourcing decision with carbon footprint tax in fashion supply chains under the return policy. He shows that adopting the return policy is able to not only alleviate the double marginalization effect in supply chains, but also increase the likelihood that the local suppliers would like to be selected. Lately, the work of Dong et al. [13] is motivated by the practices of sustainable 
fashion products and examines achievability of supply chain coordination with cap-and-trade regulation and sustainability-dependent market demand. They find that with carbon emission tax and cap-and-trade regulation consideration, the return policy is not able to coordinate the supply chain but revenue sharing contracts can.

The return policy, as one kind of supply chain contract, is a part of the supply chain strategy. Unlike a markdown money policy, the return policy may incur some unsold product returns and the cost of physical return. The return policy is a critical strategy in reverse supply chains when we consider the cost of physical return in supply chain. Tsay [14] shows several industrial cases in adopting the return policy in the fashion industry. He compares the supply chain performance of the return policy with the markdown money policy under supply chain coordination. He finds that due to the physical costs of handing returns and the relative advantages in liquidating unsold inventory, the return policy is not desirable. Our paper is different from Tsay [14] because we focus on examining the effects of the cost of physically handling returns in supply chains with respect to sustainability, rather than sustainability. $\mathrm{Hu}$ et al. [15] propose a reverse logistics cost minimization model. Given that model, they show the total reverse logistics costs can be reduced by more than $49 \%$. Krishnan et al. [8] examine the return policy in supply chains without the cost of physical return. Because they assume if the cost of physical return is extremely expensive, then the supplier might verify the amount of unsold inventory on the retailer side and pay the retailer a per-unit payment for unsold inventory. This assumption has been commonly adopted in the literature of supply chains (refer to [16,17]). However, in fashion supply chains, the logistics cost of fashion products is not extremely expensive but cannot be ignored [18]. In this paper, we incorporate the cost of physical return into the return policy.

If the cost of physical return is not considered, the return policy is equivalent to the markdown money policy [19]. Lee and Rhee [20] propose the markdown money policy with a guaranteed profit margin scheme for channel coordination in fashion apparel supply chains. They find that the supply chain is able to be coordinated under such a hybrid contract. Shen et al. [21] examine how the supplier risk-averse level affects supply chain performance under the markdown money policy. They utilize the companies' data to conduct the numerical studies. In this paper, we are motivated by the return policy practices at LX, develop the general model to examine the proposed objectives, and use LX's supply chain data to conduct the numerical study for further exploration and verification.

Sustainability analysis is intensively used in supply chain research [22]. Product returns relate to sustainability. If there are more product returns, intuitively, the degree of sustainability is lower. Culaba and Purvis [23] study manufacturing process by a sustainability analysis. Dou and Sarkisb [24] propose a sustainability analysis model to assess the outsourcing or offshoring decision in supply chains from perspectives of both facility location and supplier selection. All the literature regarding sustainability analysis is from an environmental perspective. However, sustainability analysis should include not only the environmental aspect, but also the economic one. Choi and Chiu [25] compare mean-downside-risk and mean-variance newsvendor models by a sustainability analysis. They develop the respective optimization models, identify the corresponding optimal solutions, and provide the managerial insights for sustainable fashion retailing. In sustainability analysis, they propose to examine the expected amount of leftover (which represents environmental friendliness), the expected sales to expected goods leftover ratio (which implies both environmental friendliness and economic sustainability), and the rate of return on investment (which indicates economic sustainability). 
Huscroft et al. [26] confirm the significance of sustainability analysis in reverse supply chains. In this paper, we follow the approach of sustainability analysis in Choi and Chiu [25]. Our main contribution is to examine the impact of return policy and cost of physical return on supply chains' sustainability. The existing literature has not yet examined the cost of physical return with return policy, sustainability analysis, and supply chain coordination. Our paper can fill the gap of literature.

Our paper is positioned in the area of reverse supply chains with product returns [27]. This area has been largely examined in the existing literature. Ferguson et al. [28] capture the characteristic of electronic products and examine the optimal structure of reverse supply chains. Stock and Mulki [29] empirically study the product returns in reverse supply chains. They find that manufacturers may have more products returned than retailers or wholesalers or distributors. Our paper is consistent with the work of Quariguasi Frota Neto et al. [30], where the objective of reverse supply chains is to improve the economic benefits from returned products. They also propose optimization models to ensure the sustainability of supply chains. Morana and Seuring [31] present a classification of products for end-of-life acquisition based on the marginal value of time and the product lifetime. They argue that the consumers may not return the apparel products at the end of their life cycle. Mollenkopf et al. [32] clarify the link between returns management and supply chain strategy. They find that return policy can affect product design, enhance marketing channels, and increase supply chain efficiencies. Supply chain orientation is positively associated with the effectiveness of return policies. Differences and similarities between this paper and the reviewed literature are shown in Table 1.

Table 1. Differences and similarities between this paper and the reviewed literature.

\begin{tabular}{|c|c|c|c|c|}
\hline Papers & $\begin{array}{l}\text { Return } \\
\text { Policy }\end{array}$ & $\begin{array}{c}\text { Sustainability } \\
\text { Analysis }\end{array}$ & $\begin{array}{l}\text { Supply Chain } \\
\text { Coordination }\end{array}$ & $\begin{array}{c}\text { Cost of Physical } \\
\text { Return }\end{array}$ \\
\hline Wang and Webster [5] & $\sqrt{ }$ & & $\sqrt{ }$ & \\
\hline Pasternack [7] & $\sqrt{ }$ & & $\sqrt{ }$ & \\
\hline Kurata and Yue [11] & $\sqrt{ }$ & & $\sqrt{ }$ & \\
\hline Choi $[12]$ & $\sqrt{ }$ & & $\sqrt{ }$ & \\
\hline Dong et al. [13] & $\sqrt{ }$ & & $\sqrt{ }$ & \\
\hline Tsay [14] & $\sqrt{ }$ & & $\sqrt{ }$ & $\sqrt{ }$ \\
\hline Xiao et al. [16] & $\sqrt{ }$ & & $\sqrt{ }$ & \\
\hline Yang et al. [17] & $\sqrt{ }$ & & $\sqrt{ }$ & \\
\hline Lee and Rhee [20] & & & $\sqrt{ }$ & \\
\hline Shen et al. [21] & & & $\sqrt{ }$ & \\
\hline Culabaand Purvis [23] & & $\sqrt{ }$ & & \\
\hline Dou and Sarkisb [24] & & $\sqrt{ }$ & & \\
\hline Choi and Chiu [25] & & $\sqrt{ }$ & & \\
\hline Bernon et al. [27] & $\sqrt{ }$ & & & \\
\hline Ferguson et al. [28] & $\sqrt{ }$ & & & \\
\hline Stock and Mulki [29] & $\sqrt{ }$ & & & \\
\hline Quariguasi Frota Neto et al. [30] & $\sqrt{ }$ & & & \\
\hline Morana and Seuring [31] & $\sqrt{ }$ & & & \\
\hline Mollenkopf et al. [32] & $\sqrt{ }$ & & & \\
\hline Our paper & $\sqrt{ }$ & $\sqrt{ }$ & $\sqrt{ }$ & $\sqrt{ }$ \\
\hline
\end{tabular}




\section{Model}

In this section, we first examine the benchmark case when the fashion supplier outsources retailing to the retailer without allowing the return of unsold products. We consider the supplier is the Stackelberg leader who trades with the retailer, who is the follower under the pure wholesale price contract (WS). The retailer sells a newsvendor type of fashionable product such as apparel and accessory, which is supplied by the supplier. The retailer faces an uncertain market demand, which follows a strictly positive density function $f(\cdot)$, and a distribution function $F(\cdot)$. We assume that there is a one-to-one mapping between $F(\cdot)$ and its argument. We consider that the unit product's retail price is $p$, the wholesale price is $w$, and the production $\operatorname{cost}$ is $c$. At the end of the selling season, any unsold product can be salvaged in a spot market at a unit price $v$. We consider in this paper that parameters $p, c$, and $v$ are all exogenous to the supply chain. To avoid trivial cases, we have $p>w>c>v$. The subscript $\mathrm{S}, \mathrm{R}$, and $\mathrm{SC}$ represent the supplier, the retailer, and the centralized supply chain, respectively. The expected profit functions of such a supply chain with the WS have been largely examined in literature [19]:

$$
E P \pi_{R_{-} W S}(q)=(p-w) q-(p-v) \int_{0}^{q} F(x) d x
$$

and

$$
E P \pi_{S_{-} W S}(q)=(w-c) q
$$

The optimal retailer's order quantity is $q_{R_{-} W S}^{*}=F^{-1}\left(\frac{p-w}{p-v}\right)$, the optimal supply chain's quantity is $q_{S C_{-} W S}^{*}=F^{-1}\left(\frac{p-c}{p-v}\right)$, thus, supply chain coordination cannot be achieved with the WS (i.e., $\left.q_{R_{-} W S}^{*} \neq q_{S C_{-} W S}^{*}\right)$. A summary of notations is listed in Table 2 for readers' reference.

Table 2. Summary of notation.

\begin{tabular}{cc}
\hline Notation & Meaning \\
\hline$p$ & Retail price \\
$c$ & Production cost \\
$w$ & Wholesale price \\
$b_{i}$ & Return price $(i=1,2)$ \\
$v$ & Salvage value \\
$l$ & Cost of physical return \\
$E P \pi$ & Expected Profit \\
$S C$ & Supply Chain \\
$S$ & Supplier \\
$R$ & Retailer \\
$W S$ & Wholesale price contract \\
$R P$ & Return policy \\
\hline
\end{tabular}

Next, we examine the case when the fashion supplier outsources retailing to the retailer and allows returning the unsold products to the supplier. We consider that the supplier trades with the retailer under the return policy (RP). Following the benchmark case above, we also consider the supplier is the 
Stackelberg leader and the retailer is the follower. We consider the return price is $b_{i}$, where $i=1$ or 2 , and to avoid trivial cases, we have $p>w>\max \left(b_{i}, c\right)>\min \left(b_{i}, c\right)>v$. We consider when the unsold products physically return to the supplier, one of the parties will be responsible for the cost of physical return $l$ (which includes logistics, inspection, repackaging, etc.). Thus, there are two scenarios: (1) the retailer bears the cost of physical return $l$; and (2) the supplier bears the cost of physical return $l$. We have the following expected profit of the supply chain as shown in Table 3.All of the technical proofs are relegated to the Appendix.

Table 3. The functions of expected profit in supply chain with the return policy (RP).

\begin{tabular}{ccc}
\hline & Scenario 1: the Retailer Bears $\boldsymbol{l}$ & Scenario 1: the Supplier Bears $\boldsymbol{l}$ \\
\hline Retailer & $E P \pi_{R_{-} R P 1}(q)=(p-w) q-\left(p-b_{1}+l\right) n(q) \cdot(3)$ & $E P \pi_{R_{-} R P 2}(q)=(p-w) q-\left(p-b_{2}\right) n(q) \cdot(4)$ \\
Supplier & $E P \pi_{S_{-} R P 1}(q)=(w-c) q-\left(b_{1}-v\right) n(q) \cdot(5)$ & $E P \pi_{S_{-} R P 2}(q)=(w-c) q-\left(b_{2}-v+l\right) n(q) \cdot(6)$ \\
Supply Chain & $E P \pi_{S C_{-} R P 1}(q)=(p-c) q-(p-v+l) n(q) \cdot(7)$ & $E P \pi_{S C_{-} R P 2}(q)=(p-c) q-(p-v+l) n(q) \cdot(8)$ \\
\hline \multicolumn{4}{c}{ Note: $n(q)=\int_{0}^{q} F(x) d x}$.
\end{tabular}

After taking the first and second derivatives of the retailer's and supply chain's profit with respect to $q$, we obtain that the retailer's optimal order quantity in Scenario 1 is $q_{R_{-} R P 1}^{*}=F^{-1}\left(\frac{p-w}{p-b_{1}+l}\right)$, the retailer's optimal order quantity in Scenario 2 is $q_{R_{-} R P 2}^{*}=F^{-1}\left(\frac{p-w}{p-b_{2}}\right)$, and the optimal supply chain quantity is $q_{S C_{-} R P}^{*}=F^{-1}\left(\frac{p-c}{p-v+l}\right)$. It is not surprising that the supply chain is able to achieve coordination (i.e., $q_{R_{-} R P}^{*}=q_{S C_{-} R P}^{*}$ ) with the RP (for supply chain coordination with the return policy, please refer to $[19,33])$. Then, we obtain that when the supply chain achieves coordination, the corresponding return prices are:

$$
b_{1}=p+l-\frac{(p-v+l)\left(p-w_{1}\right)}{(p-c)}
$$

and:

$$
b_{2}=p-\frac{(p-v+l)\left(p-w_{2}\right)}{(p-c)}
$$

Proposition 3.1. Let the return price be $b_{i}$, where $i=1$, 2. (a) When $w_{1} \geq w_{2}$, it is always true that $b_{1}>b_{2}$; (b) $b_{1}$ is increasing in $l$ and $b_{2}$ is decreasing in $l$.

Proposition 3.2. Both $q_{R_{-} R P 1}^{*}$ and $q_{S C_{-} R P}^{*}$ are decreasing in $l$, and $q_{R_{-} R P 2}^{*}$ is independent on $l$.

Proposition 3.1 implies the feature of return prices in such supply chains. Proposition 3.1a indicates that if the wholesale price under Scenario 1 is not lower than that under Scenario 2, the return price under Scenario 1 is always higher than that under Scenario 2. Under the return policy, the supplier pays $b_{i}$ to the retailer at the end of selling season. According to Proposition 3.1b, we find that the cost of physical return is always associated with contract parameters such as return price $b_{i}$. Specifically, $b_{1}$ is increasing in $l$ (recall in Scenario 1, the retailer bears $l$ ) but $b_{2}$ is decreasing in $l$ (recall in Scenario 2, the supplier bears $l$ ). When the retailer bears the cost of physical return, a higher $l$ leads to a higher return 
price, and when the supplier bears the cost of physical return, a higher $l$ leads to a lower return price. In other words, when the cost of physical return is less, in Scenario 2, the supplier would pay less return price. Thus, this implies that the cost of physical return is at least partially borne by the supplier, no matter who is responsible for it in reality.

Proposition 3.2 shows the relationship between the optimal order quantities and the cost of physical returns in supply chains. In Scenario 2, the supplier bears the cost of physical return and it is not surprising that $q_{R_{-} R P 2}^{*}$ is independent on the cost of physical return. When the supply chain achieves supply chain coordination, the retailer will involuntarily order the optimal supply chain quantity $q_{S C_{-} R P}^{*}$, which is decreasing in $l$. It is well known that achieving supply chain coordination can help the individual parties in supply chains behave in a way which optimizes the whole supply chain system [21]. Hence, when we consider the case that the supply chain is coordinated (i.e., centrally optimized), namely, the optimal quantity is $q_{S C_{-} R P}^{*}$. In the following sections, our analysis is based on $q_{S C_{-} R P}^{*}$.

\section{Sustainability Analysis}

Sustainability is important when supply chain managers make the operational decisions from both environmental and economic perspectives. In this section, we follow the approach of Choi and Chiu [25] and conduct a sustainability analysis to examine supply chain performance with respect to sustainability. We consider that a coordinating sustainable fashion supply chain is quantified by a few sustainability measurements, including the expected quantity of goods leftover $L(q)$ (which represents environmental friendliness), the ratio of expected sales to expected quantity of goods leftover $\operatorname{SLR}(q)$ (which implies both environmental friendliness and economic sustainability), and the expected rate of return on investment $R(q)$ (which indicates economic sustainability). The three measures above have been well studied in Choi and Chiu [25] for the degree of supply chain sustainability and brought some meaning behind sustainability (to be specific, a low $L(q)$, or a high $\operatorname{SLR}(q) / R(q)$ is more desirable in supply chains with respect to both economic and environmental sustainability). Based on the model of Choi and Chiu [25], we have the following equations.

$$
\begin{gathered}
L(q)=E\left[(q-x)^{+}\right]=\int_{0}^{q} F(x) d x \\
S L R(q)=\frac{E\left[q-(q-x)^{+}\right]}{L(q)}=\frac{q}{L(q)}-1 \\
R(q)=\frac{E P \pi_{S C}}{c q}
\end{gathered}
$$

They indicate that $L(q)$ is an increasing function of $q ; R(q)$ is a decreasing function of $q, \forall q \geq 1$; $\operatorname{SLR}(q)$ is a decreasing function of $q, \forall q \geq 1$. Then, we have the following results.

Proposition 4.1. $L\left(q_{S C_{-} R P}^{*}\right)$ is a decreasing function of l, but both $\operatorname{SLR}\left(q_{S C_{-} R P}^{*}\right)$ and $R\left(q_{S_{-} R P}^{*}\right)$ are increasing functions of $l, \forall q_{S C_{-} R P}^{*} \geq 1$.

Proposition 4.2. Comparing the WS with the RP, we have $L\left(q_{R_{-} W S}^{*}\right)<L\left(q_{S C_{-} R P}^{*}\right)$, $\operatorname{SLR}\left(q_{R_{-} W S}^{*}\right)>\operatorname{SLR}\left(q_{S C_{-} R P}^{*}\right)$, and $R\left(q_{R_{-} W S}^{*}\right)>R\left(q_{S C_{-} R P}^{*}\right)$. 
Proposition 4.1 implies that the cost of physical return is significantly affecting both economic and environmental sustainability factors. Specifically, if the cost of physical return is higher, the expected quantity of goods leftover is lower, but the ratio of expected sales to expected quantity of goods leftover and the expected rate of return on investment are higher. Recall that a low $L(q)$ or a high $\operatorname{SLR}(q) / R(q)$ is more desirable in supply chains with respect to sustainability. When we compare the sustainability results under the RP with those under the WS, we can see, as shown in Proposition 4.2, that under the RP, the expected quantity of goods leftover is higher, and the ratio of expected sales to expected quantity of goods leftover and the expected rate of return on investment, are lower than those under the WS. In other words, from the whole supply chain perspective, the WS is more sustainable than the coordinating RP.

Both Proposition 4.1 and Proposition 4.2 deliver some important managerial insights. Specifically, we find that a low logistic cost for returning products may not be beneficial to supply chain sustainability. As a matter of fact, this can be partially explained that if the logistic cost is high, the retailer will order less and the leftovers at the end of selling season will be naturally reduced. Moreover, recall that the expected amount leftover represents environmental friendliness, the rate of return on investment indicates economic sustainability, and ratio of the expected sales to expected goods leftover implies both environmental friendliness and economic sustainability. We suggest that for fashion companies who care about environmental friendliness, they should focus on reducing $L(q)$; who care about economic sustainability, they should focus on increasing $R(q)$; who care about both economic and environmental sustainability, they should focus on enhancing $\operatorname{SLR}(q)$. Our analysis shows a comprehensive measurement for sustainable supply chains. Supply chain managers can adopt our approach to assess the degree of sustainability in supply chains.

\section{Numerical Study}

In this section, we conduct the numerical study by using one real fashion company's data (i.e., LX). The company's data is given by managers of the respective company. We focus on studying how the cost of physical return affects supply chain performance with respect to the coordinating return policy in the real fashion business environment. As introduced before, LX is a supplier of fashion products, in which the unit product cost is $c=160$, the unit salvage price is $v=60$, and the unit product price is $p=500$. These rates are from the manager of LX for one of its certain fashion products and consistent with the industrial norm in the fashion industry (fashion apparel is one kind of high-profit product with $p / c>50 \%$ [34]). The real market situation is still well reflected even though the cost-revenue data values are scaled for confidential purposes. The quality of any research findings will not be affected by this scaling. Market demand for the product is estimated to be normally distributed with mean 100 and variance 900, which are the estimates from the manager of the respective company. Table 4 represents the numerical analysis for LX.

Table 4. Numerical analysis of LX.

\begin{tabular}{cccccc}
\hline$l$ & $q_{S C_{-} R P}^{*}$ & $E P_{S C}\left(q_{S C_{-} R P}^{*}\right)$ & $L\left(q_{S C_{-} R P}^{*}\right)$ & $S R L\left(q_{S C_{-} R P}^{*}\right)$ & $R\left(q_{S C_{-} R P}^{*}\right)$ \\
\hline 1 & 122.2619 & $29,993.75$ & 26.2478 & 3.657985 & 1.533274 \\
4 & 121.7492 & $29,915.64$ & 25.8538 & 3.709141 & 1.535721 \\
\hline
\end{tabular}


Table 4. Cont.

\begin{tabular}{cccccc}
\hline$l$ & $q_{S C_{-} R P}^{*}$ & $E P_{S C}\left(q_{S C_{-} R P}^{*}\right)$ & $L\left(q_{S C_{-} R P}^{*}\right)$ & $S R L\left(q_{S C_{-} R P}^{*}\right)$ & $R\left(q_{S C_{-} R P}^{*}\right)$ \\
\hline 7 & 121.2496 & $29,838.65$ & 25.4725 & 3.760018 & 1.538080 \\
10 & 120.7623 & $29,762.79$ & 25.1031 & 3.810653 & 1.540360 \\
13 & 120.2868 & $29,688.03$ & 24.7450 & 3.861056 & 1.542565 \\
16 & 119.8225 & $29,614.31$ & 24.3977 & 3.911223 & 1.544696 \\
19 & 119.3689 & $29,541.62$ & 24.0606 & 3.961178 & 1.546760 \\
22 & 118.9255 & $29,469.93$ & 23.7332 & 4.010934 & 1.548760 \\
25 & 118.4918 & $29,399.20$ & 23.4151 & 4.060488 & 1.550698 \\
28 & 118.0675 & $29,329.42$ & 23.1058 & 4.109863 & 1.552578 \\
31 & 117.6520 & $29,260.58$ & 22.8049 & 4.159068 & 1.554403 \\
34 & 117.2451 & $29,192.61$ & 22.5121 & 4.208094 & 1.556174 \\
37 & 116.8465 & $29,125.47$ & 22.2271 & 4.256937 & 1.557892 \\
40 & 116.4557 & $29,059.22$ & 21.9494 & 4.305642 & 1.559564 \\
43 & 116.0724 & $28,993.77$ & 21.6788 & 4.354192 & 1.561189 \\
46 & 115.6965 & $28,929.13$ & 21.4150 & 4.402593 & 1.562770 \\
49 & 115.3276 & $28,856.57$ & 21.1755 & 4.446275 & 1.563837 \\
52 & 114.9655 & $28,802.16$ & 20.9067 & 4.498977 & 1.565805 \\
55 & 114.6098 & $28,762.12$ & 20.6166 & 4.559104 & 1.568480 \\
58 & 114.2605 & $28,678.21$ & 20.4224 & 4.594860 & 1.568686 \\
\hline
\end{tabular}

From Table 4, we can see that when the cost of physical return is higher, the expected profit of supply chains under coordination is lower. This numerical result implies that the cost of physical return may hurt supply chain performance in terms of expected profit. For sustainability analysis, the results are consistent with the analytical findings. If the cost of physical return is decreasing, the expected quantity of goods leftover is higher, and both the ratio of expected sales to expected quantity of goods leftover and the expected rate of return on investment are increasing. Moreover, when supply chain performance in terms of expected profit is high, the expected quantity of goods leftover is high, and both the ratio of expected sales to expected quantity of goods leftover and the expected rate of return on investment are low.

\section{Conclusions}

Companies have experienced great gains through outsourcing [35]. In this paper, we examine a two-echelon fashion supply chain with one supplier (i.e., the brand owner) and one retailer selling a short-life fashion product under a well-adopted return policy. We study the effects of unsold products in an outsourcing fashion supply chain. We find several interesting results from analysis.

(1) We examine how the cost of physical return affects supply chains. We find that the cost of physical return is at least partially borne by the supplier, no matter who bears this cost in reality. This implies that when the supplier offers the return policy, he has to consider the possibility of a product's return and the cost of physical return.

(2) We study whether the cost of physical return is significantly affecting the sustainability factors. We find that if the cost of physical return is relatively high, the expected quantity of goods leftover is relatively low, and both the ratio of expected sales to expected quantity of goods 
leftover and the expected rate of return on investment are relatively high. This finding implies a low logistic cost for returning products may not be beneficial to supply chain sustainability. The fashion supply chain managers can adopt our investigated sustainability factors to assess the degree of sustainability in supply chains.

(3) We compare the economic sustainability results under the return policy with those under the benchmark wholesale price contract. We find that, under the return policy, the expected quantity of goods leftover is higher, and the ratio of expected sales to expected quantity of goods leftover and the expected rate of return on investment are lower than those under benchmark wholesale price contracts. Therefore, from the entire supply chain perspective, the WS is more sustainable than the coordinating RP.

For future research, this study is subject to three main limitations on potentially fruitful directions. First, we only focus on studying the effects of the cost of physical return in the return policy instead of the entire life cycle of products such as carbon emissions in transportation. In future research, it would be interesting to incorporate the cap-and-trade regulation and carbon tax with the return policy. Second, we consider the retail price as exogenous in supply chains because we focus on examining the impact of the cost of physical return. In future research, it would be more interesting to investigate the association between the endogenous retail price and the cost of physical return. Third, in the fashion industry, product returns are part of the customer value strategy [36] and important resources in secondary markets such as outlet stores and e-commerce channels [37]. In future research, it would be interesting to examine the effects of product return on market demand.

\section{Acknowledgments}

The authors would like to thank an editor and two anonymous referees for their constructive comments and suggestions on earlier versions of this paper. Bin Shen is supported by "the Shanghai Pujiang Program (14PJ1400200)" and "National Natural Science Foundation of China (71401029)"; Qingying Li is supported by “the Fundamental Research Funds for the Central Universities". Any errors or omissions remain the sole responsibility of the authors.

\section{Author Contributions}

Bin Shen designed the research. Bin Shen and Qingying Li performed the research and wrote the paper. All authors read and approved the final manuscript.

\section{Appendix-All Proofs}

Proof of Proposition 3.1. For (a), $b_{1}-b_{2}=l+\frac{(p-v+l)\left(w_{1}-w_{2}\right)}{(p-c)}$. Since $p>c>v$, we can observe that when $w_{1} \geq w_{2}$, it is always true that $b_{1}>b_{2}$. For $(\mathrm{b}), d b_{1} / d l=1-\frac{\left(p-w_{1}\right)}{(p-c)}$. Since $p>w>c$, we can know that $d b_{1} / d l>0$; and $d b_{2} / d l=-\frac{\left(p-w_{2}\right)}{(p-c)}<0$, thus we can know that $d b_{2} / d l<0$. (Q.E.D.) 
Proof of Proposition 3.2. We know $q_{R_{-} R P 1}^{*}=F^{-1}\left(\frac{p-w}{p-b_{1}+l}\right)$ and $q_{S C_{-} R P}^{*}=F^{-1}\left(\frac{p-c}{p-v+l}\right)$. After differentiating with $l$, we can easily find that $d q_{R_{-} R P 1}^{*} / d l<0$ and $d q_{S_{-} R P}^{*} / d l<0$. Then, we can obtain that when $l$ is increasing, both $q_{R_{-} R P 1}^{*}$ and $q_{S C_{-} R P}^{*}$ are decreasing. (Q.E.D.)

Proof of Proposition 4.1. Since $L(q)$ is an increasing function of $q$, and $q_{S C_{-} R P}^{*}$ are decreasing in $l$, we can have $L\left(q_{S C_{-} R P}^{*}\right)$ as a decreasing function of $l$. Moreover, $R(q)$ is a decreasing function of $q, \forall q \geq 1$ and $q_{S C_{-} R P}^{*}$ are decreasing in $l$, thus we can have $R\left(q_{S C_{-} R P}^{*}\right)$ as an increasing function of $l$, $\forall q_{S C_{-} R P}^{*} \geq 1$. In addition, $\operatorname{SLR}(q)$ is a decreasing function of $q, \forall q \geq 1$ and $q_{S C_{-} R P}^{*}$ are decreasing in $l$, thus we can have $\operatorname{SLR}\left(q_{S C_{-} R P}^{*}\right)$ as an increasing function of $l, \forall q_{S C_{-} R P}^{*} \geq 1$. (Q.E.D.)

Proof of Proposition 4.2. Comparing the optimal order quantities between the WS and the RP, we know $q_{R_{-} W S}^{*}<q_{S C_{-} R P}^{*}$. Because $L(q)$ is an increasing function of $q ; R(q)$ is a decreasing function of $q, \forall q \geq 1$; $\operatorname{SLR}(q)$ is a decreasing function of $q, \forall q \geq 1$. Then we have the following results $L\left(q_{R_{-} W S}^{*}\right)<L\left(q_{S C_{-} R P}^{*}\right)$, $\operatorname{SLR}\left(q_{R_{-} W S}^{*}\right)>\operatorname{SLR}\left(q_{S C_{-} R P}^{*}\right)$, and $R\left(q_{R_{-} W S}^{*}\right)>R\left(q_{S C_{-} R P}^{*}\right)$. (Q.E.D. $)$

\section{Conflicts of Interest}

The authors declare no conflict of interest.

\section{References}

1. Hausman, W.; Thorbeck, J. Fast fashion: Quantifying the benefits. In Innovative Quick Response Programs in Logistics and Supply Chain Management, International Handbooks Information System; Springer: Berlin, Germany, 2010; pp. 315-329.

2. Mostard, J.; Teunter, R. The newsboy problem with resalable returns: A single period model and case study. Eur. J. Oper. Res. 2006, 169, 81-96.

3. Shen, B. Sustainable Fashion Supply Chain: Lessons from H\&M. Sustainability 2014, 6, 6239-6249.

4. Shen, B.; Zheng, J.; Chow, P.; Chow, K. Perception of fashion sustainability in online community. J. Text. Inst. 2014, 105, 971-979.

5. Blackburn, J.D.; Guide, V.D.R.; Souza, G.C.; van Wassenhove, L.N. Reverse supply chains for commercial returns. Calif. Manag. Rev. 2004, 46, 6-22.

6. Shen, B.; Chow, P.S.; Choi, T.M. Supply Chain Contracts in Fashion Department Stores: Coordination and Risk Analysis. Math. Prob. Eng. 2014, 2014, Article 954235.

7. Pasternack, B.A. Optimal pricing and returns policies for perishable commodities. Mar. Sci. 1985, 4, 166-176.

8. Krishnan, H.; Kapuscinski, R.; Butz, D.A. Coordinating contracts for decentralized supply chains with retailer promotional effort. Manag. Sci. 2004, 50, 48-63.

9. Cachon, G.P.; Lariviere, M.A. Supply chain coordination with revenue sharing contracts: Strengths and limitations. Manag. Sci. 2005, 51, 30-44.

10. Donohue, K.L. Efficient supply contracts for fashion goods with forecast updating and two production modes. Manag. Sci. 2000, 46, 1397-1411. 
11. Kurata, H.; Yue, X. Trade promotion mode choice and information sharing in fashion retail supply chains. Int. J. Prod. Econ. 2008, 114, 507-519.

12. Choi, T.M. Optimal apparel supplier selection with forecast updates under carbon emission taxation scheme. Comp. Oper. Res. 2013, 40, 2646-2655.

13. Dong, C.W.; Shen, B.; Chow, P.S.; Yang, L.; Ng, C.T. Sustainability investment under cap-and-trade regulation. Ann. Oper. Res. 2014, doi:10.1007/s10479-013-1514-1.

14. Tsay, A.A. Managing retail channel overstock: Markdown money and return policy. J. Ret. 2001, 77, 457-492.

15. Hu, T.L.; Sheu, J.B.; Huang, K.H. Reverse logistics cost minimization model for the treatment of hazardous wastes. Transp. Res. Part E 2002, 38, 457-473.

16. Xiao, T.; Shi, K.; Yang, D. Coordination of a supply chain with consumer return under demand uncertainty. Int. J. Prod. Econ. 2010, 124, 171-180.

17. Yang, D.; Choi, T.M.; Xiao, T.J.; Cheng, T.C.E. Coordinating a two-supplier and one-retailer supply chain with forecast updating. Automatica 2011, 47, 1317-1329.

18. Shah, R. Fixing how clothes fit you can reshape online retail logistics. Available online: http://www.forbes.com/sites/rawnshah/2014/04/11/fixing-how-clothes-fit-you-can-reshape-onlineretail-logistics/ (accessed on 1 November 2014).

19. Cachon, G. Supply chain coordination with contracts. In Handbooks in Operations Research and Management Science: Supply Chain Management; Graves, S., de Kok, T., Eds.; North Holland: Amsterdam, The Netherlands, 2003.

20. Lee, C.H.; Rhee, B.D. Optimal guaranteed profit margins for both vendors and retailers in the fashion apparel industry. J. Ret. 2008, 83, 325-333.

21. Shen, B.; Choi, T.M.; Wang, Y.; Lo, C. The coordination of fashion supply chains with a risk averse supplier under the markdown money policy. IEEE Trans. Syst. Man Cyber. Syst. 2013, 43, 266-276.

22. De Brito M.P.; van der Laan, E.A. Supply Chain Management and Sustainability: Procrastinating Integration in Mainstream Research. Sustainability 2010, 2, 859-870.

23. Culaba, A.B.; Purvis, M.R.I. A methodology for the life cycle and sustain- ability analysis of manufacturing processes. J. Clean. Prod.1999, 7, 435-445.

24. Dou, Y.; Sarkis, J. A joint location and outsourcing sustainability analysis for a strategic offshoring decision. Int. J. Prod. Res. 2010, 48, 567-592.

25. Choi, T.M.; Chiu, C.H. Mean-downside-risk and mean-variance newsvendor models: Implications for sustainable fashion retailing. Int. J. Prod. Econ. 2012, 135, 552-560.

26. Huscroft, J.; Hazen, B.; Hall, D.; Skipper, J.; Hanna, J. Reverse logistics: Past research, current management issues, and future directions. Int. J. Logist. Manag. 2013, 24, 304-327.

27. Bernon, M.; Upperton, J.; Bastl, M.; Cullen, J. An exploration of supply chain integration in the retail product returns process. Int. J. Phys. Distrib. Logist. Manag. 2013, 43, 586-608.

28. Ferguson, M.E.; Fleischmann, M.; Souza, G.C. A profit-maximizing approach to disposition decisions for product returns. Dec. Sci. 2011, 42, 773-798.

29. Stock, J.R.; Mulki, J.P. Product returns processing: An examination of practices of manufacturers, wholesalers/distributors, and retailers. J. Bus. Logist. 2009, 30, 33-62. 
30. Quariguasi Frota Neto, J.; Walther, G.; Bloemhof-Ruwaard, J.M.; van Nunen, J.A.E.E.; Spengler, T. From closed loop to sustainable supply chains: The WEEE case. Int. J. Prod. Res. 2010, 48, 4463-4481.

31. Morana, R.; Seuring, S. End-of-life returns of long-lived products from end customer-Insights from an ideally set up closed-loop supply chain. Int. J. Prod. Res. 2007, 45, 4423-4437.

32. Mollenkopf, D.; Russo, I.; Frankel, R. The returns management process in supply chain strategy. Int. J. Ret. Distr. Manag. 2007, 37, 568-592.

33. Choi, T.M.; Li, D.; Yan, H.M. Mean-variance analysis of a single supplier and retailer supply chain under a returns policy. Eur. J. Oper. Res. 2008, 184, 356-376.

34. Schweitzer, M.; Cachon, G. Decision bias in the newsvendor problem: Experimental evidence. Manag. Sci. 2000, 46, 404-420.

35. Alessio, I.; Rebecca, B. The 18 C's model for a successful long-term outsourcing arrangement. Ind. Mark. Manag. 2012, 41, 1071-1080.

36. Russo, I.; Cardinali, S. Product returns and customer value: A footware industry case. In Modelling Value, Contributions to Management Science, Part 2; Jodlbauer, H., Olhager, J., Schonberger, R.J., Eds.; Springer: Berlin, Germary, 2012; pp. 79-97.

37. Castelli, C.M.; Brun, A. Alignment of retail channels in the fashion supply chain: An empirical study of Italian fashion retailers. Int. J. Ret. Distr. Manag. 2010, 38, 24-44.

(C) 2015 by the authors; licensee MDPI, Basel, Switzerland. This article is an open access article distributed under the terms and conditions of the Creative Commons Attribution license (http://creativecommons.org/licenses/by/4.0/). 